\title{
A monitoring network for anomalous propagation of aeronautical VHF radio waves due to sporadic E in Japan
}

\author{
Keisuke Hosokawa ${ }^{{ }^{*}}$ D , Jun Sakai ${ }^{1}$, Ichiro Tomizawa ${ }^{2}$, Susumu Saito ${ }^{3}$, Takuya Tsugawa ${ }^{4}$, Michi Nishioka ${ }^{4}$
} and Mamoru Ishii ${ }^{4}$

\begin{abstract}
We introduce a network observation of anomalous long-distance propagation of aeronautical navigation (NAV) very high-frequency (VHF) radio waves due to sporadic E layer (Es). The system has been operative since May 2019 at 6 stations in Japan. The receiver consists of a log-periodic antenna, air-band filter, software-defined radio and small computer which is capable of recording the strength of radio signals in the frequency band from 98 to $118 \mathrm{MHz}$ with a temporal resolution of $2 \mathrm{~s}$. The receiver covers not only the NAV band including VHF omnidirectional radio range (VOR), instrument landing system localizer (ILS LOC) and ground-based augmentation system VHF data broadcast (GBAS VDB) from 108 to $118 \mathrm{MHz}$, but also broadcasting channels from 98 to $108 \mathrm{MHz}$. Soon after the start of the full operation of the network observation, a strong Es event was detected by an ionosonde in Tokyo during the daytime on July 4, 2019, in which foEs (critical frequency of Es) was sometimes higher than $15 \mathrm{MHz}$. The VHF radio wave monitoring system detected multiple signatures of Es anomalous propagation (EsAP) at all the stations extending from Okinawa to Hokkaido. At some stations, the EsAP signatures continued for a few hours with some brief intervals of disappearance. The observed correspondence between the enhancement of foEs and the occurrence of anomalous propagation confirmed that an extreme electron density enhancement within Es caused the anomalous longdistance propagation of VHF NAV signals. The data from this network observation can be browsed at http://gwave .cei.uec.ac.jp/cgi-bin/vor/vhf.cgi in near real-time basis. This near real-time monitoring capability allows people in the aeronautical operation community such as air navigation service providers, pilots, and airline engineers to check the propagation environment of VHF NAV signals online, which contributes to a mitigation of ionospheric space weather impacts on the aeronautical navigation systems. Not only that the current method for detecting Es in a wide area can be used to visualize the spatial distribution of Es in two-dimensional fashion through a combination of other observation techniques such as ionosondes and total electron content (TEC) measurements using Global Navigation Satellite System (GNSS) signals.
\end{abstract}

Keywords: Ionosphere, Sporadic E, Radio propagation, Aeronautical navigation system, Software radio

\section{Background}

The sporadic E (Es) is known as a layer of increased electron density in the ionospheric $\mathrm{E}$ region having very thin altitudinal thickness (Whitehead 1989; Mathews 1998;

\footnotetext{
*Correspondence: keisuke.hosokawa@uec.ac.jp

${ }^{1}$ University of Electro-Communications, Chofugaoka 1-5-1, Chofu, Tokyo

182-8585, Japan

Full list of author information is available at the end of the article
}

Haldoupis 2011). Es is frequently observed during summer months from May to August in the Northern Hemisphere and its occurrence has a characteristic diurnal and semi-diurnal variations (e.g., Wu et al. 2005). It has been suggested that Es at mid-latitudes is produced by a concentration of metallic ions of meteor origin by a vertical shear in the neutral wind (e.g., Whitehea 1989). Recently, Shinagawa et al. (2017) demonstrated using a 
self-consistent atmosphere-ionosphere coupled model called GAIA (Ground-to-topside model of Atmosphere and Ionosphere for Aeronomy) that the vertical wind shear is the primary parameter determining the geographical distribution and seasonal variation of Es activity. In addition to these modeling studies, several new techniques have been proposed for visualizing the twodimensional distribution of Es, for example ground-based passive radio observation (Rice et al. 2011), GPS-TEC (Maeda and Heki 2014, 2015) and InSAR (Maeda et al. 2016; Furuya et al. 2017). Combination of such 2D observations with the recent modeling efforts will enable us to fully understand the detailed dynamical characteristics and generation mechanisms of Es in the coming decade.

It has been known for a long time that the Es layer could cause anomalous propagation of VHF radio waves such as those used for FM radio and analog TV, by reflecting waves which normally penetrate through the ionosphere. Recently, Sakai et al. (2019) demonstrated that such anomalous propagation occurs in the VHF signals of aeronautical navigation (NAV) systems (ICAO (International Civil Aviation Organization) 2018) such as VHF omnidirectional radio range (VOR), instrument landing system localizer (ILS LOC) and ground-based augmentation system VHF data broadcast (GBAS VDB) which use frequencies in the band from 108 to $118 \mathrm{MHz}$. Figure 1 is a schematic diagram showing such anomalous propagation for the case of VOR signals. Normally, VHF NAV signals are received within the radio horizon because the frequency of those waves is sufficiently high to penetrate all the way through the ionosphere (Davis et al. 1959). Then, those radio waves are used for navigation by aircrafts operative within a distance of $\sim 200 \mathrm{~km}$ from radio sources (normal propagation on the left-hand side of Fig. 1). However, when Es appears and the electron density at around $100 \mathrm{~km}$ is high enough to reflect VHF radio signals with larger incident angles, the waves can propagate beyond a certain distance (anomalous propagation shown on the right-hand side of Fig. 1). It is known that such anomalous propagation occurs in a distance range of $600-2500 \mathrm{~km}$ from the radio source, which has a potential to cause an interference with normal propagation signals (Sakai et al. 2019). Within distances between 200 and $600 \mathrm{~km}$ from the source, radio waves are observed by neither normal nor anomalous propagation, and this area is called skip zone (Davies 1969).

Continuous observations of anomalous long-range propagation of VHF radio waves due to Es (Es anomalous propagation: EsAP) allow us to evaluate the impact of Es on the aeronautical NAV systems. At the same time, it would be possible to map the 2D spatial distribution of Es, that can affect the NAV systems, by monitoring the EsAP signals from widely distributed VOR, ILS LOC and GBAS VDB stations. Recently, it is being recognized among the ICAO community that the Es layer has a potential to introduce anomalous propagation in the frequency band of aeronautical navigation and communication (ICAO APANPIRG CNS-SG ISTF/6-WP/4 2016; ICAO APANPIRG CNS-SG/20-WP/21 2016). In this sense, the information on the Es layer could be a part of space weather information. To date, however, the number of ground-based monitoring stations for aeronautical VHF signals has been limited. For example, conventional ionosonde observation of Es requires relatively larger costs for operation and efforts for keeping the license for radio transmission. In addition, the ionosondes are able to monitor the appearance of Es only above the observation sites. Thus, it has still been difficult to evaluate and monitor the potential impact of Es on the VHF radio waves used for aeronautical navigation and communication.

To routinely monitor the occurrence of EsAP and further visualize the spatial distribution of Es, we have started a network observation of VHF NAV signals since May 2019 at 6 stations in Japan, extending from the southernmost station in Okinawa to the northernmost station in Hokkaido. The real-time data from all the 6

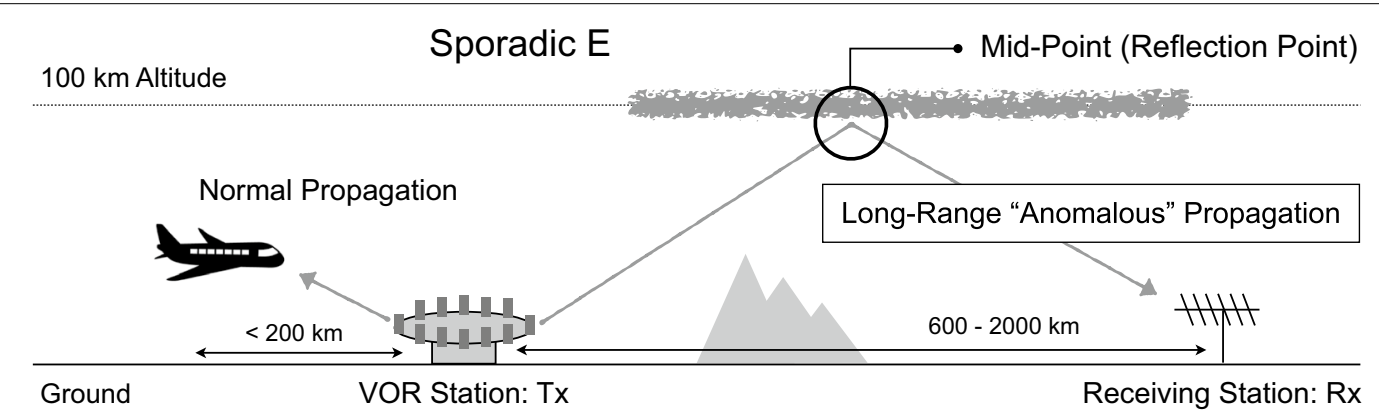

Fig. 1 A sketch anomalous long-distance propagation of $\mathrm{VHF}$ radio waves for aeronautical navigation system due to sporadic $\mathrm{E}$ 
stations are available through the website (http://gwave .cei.uec.ac.jp/cgi-bin/vor/vhf.cgi). The goal of this network observation is to map the reflection points of EsAP signals on the geographic coordinate system to visualize the impact area of Es on the VHF NAV systems. This paper introduces the technical details of the monitoring system and presents an initial result of Es observations during the summer months of 2019.

\section{Observation system}

To monitor the occurrence of EsAP in a large area, we have installed observation systems into 6 stations in Japan. Figure 2 shows the block diagram of the system including the near real-time monitoring function. Incoming aeronautical NAV signals are received by a logperiodic antenna (CLP5130-1 or CLP5130-3) and the received signal is filtered by a band-pass filter called "airband filter" (AOR ABF128) to cut unwanted signals in an urban area. Note that this air-band filter is used only for observations in urban areas (Chofu and Oarai stations). The specifications/settings of the log-periodic antenna and the air-band filter are provided in Table 1. The signal is sampled by a software-defined radio (SDR: NI USRP2920), which is connected to a small PC, with a sampling rate of $20 \mathrm{MHz}$. The sampled raw waveform data from SDR are processed (Fast Fourier Transformed: FFT) by a software written in LabVIEW to derive a frequency spectrum every 2 s. 10,000 samples obtained in $0.5 \mathrm{~ms}$ are used for the FFT process and the corresponding resolution of the frequency spectrum is $2 \mathrm{kHz}$. From the frequency spectrum, the signal intensity is derived on-site for each of all the 193 NAV channels with a temporal resolution of $2 \mathrm{~s}$. The frequency separation between the consecutive NAV channels is as short as $25 \mathrm{kHz}$; thus, the frequency resolution of the FFT process in the current analysis, which is $2 \mathrm{kHz}$, is sufficient for distinguishing neighboring channels.

These signal intensity values, in decibel-milliwatts $(\mathrm{dBm})$ per channel, are then converted to the antenna input value (electric field strength) using the gain-correction factors obtained through the calibration work at the time of installation. This gain-correction process allows us to compare the signal intensity values from all the stations in a direct manner. These reduced data generated on-site are finally transferred to the central data server at University of Electro-Communications through the internet every $1 \mathrm{~h}$. At the server side, quick-look data plots are created using all the processed data arrived from the 6 stations together with additional Es data obtained by a network of ionosondes operated by National Institute of Information and Communications Technology (NICT) located at 4 places in Japan. The near real-time plots are available through the internet (http://gwave.cei.uec. ac.jp/cgi-bin/vor/vhf.cgi) and refreshed every $1 \mathrm{~h}$. When

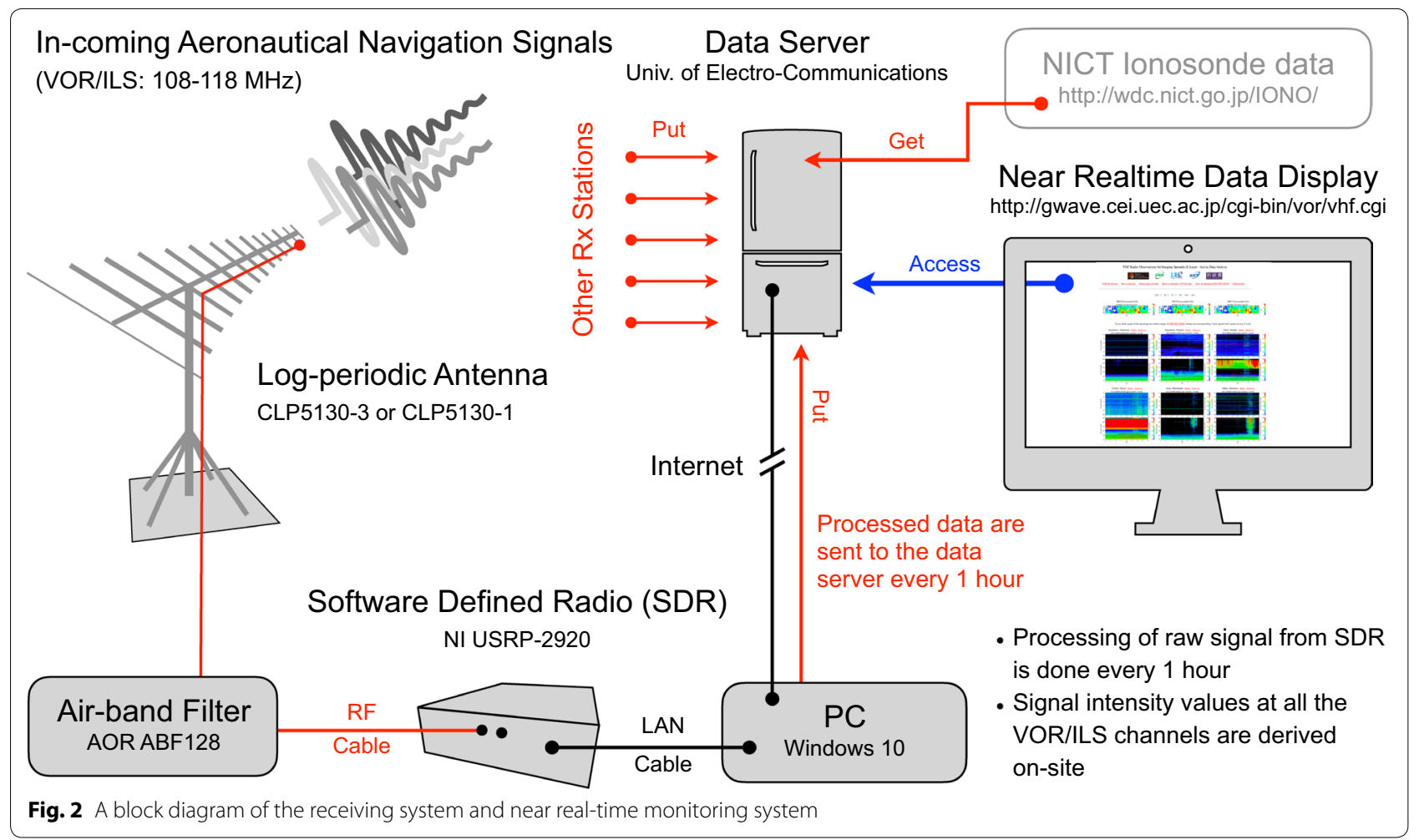


Table 1 Specifications of receiver components

\begin{tabular}{lcccccc}
\hline $\begin{array}{l}\text { Location (CODE) } \\
\text { (a) Geographic coordinates }\end{array}$ & $\begin{array}{l}\text { Sarobetsu (SAR) } \\
\text { Sugadaira (SGD) }\end{array}$ & Oarai (ORI) & Chofu (CF2) & Kure (KUR) & Onna (ONA) \\
\hline Latitude & $45.16^{\circ} \mathrm{N}$ & $36.42^{\circ} \mathrm{N}$ & $36.33^{\circ} \mathrm{N}$ & $35.66^{\circ} \mathrm{N}$ & $34.24^{\circ} \mathrm{N}$ & $26.50^{\circ} \mathrm{N}$ \\
Longitude & $141.75^{\circ} \mathrm{E}$ & $138.32^{\circ} \mathrm{E}$ & $140.58^{\circ} \mathrm{E}$ & $139.54^{\circ} \mathrm{E}$ & $132.53^{\circ} \mathrm{E}$ & $127.85^{\circ} \mathrm{E}$ \\
\hline
\end{tabular}

\section{(b) Antenna specification}

\begin{tabular}{|c|c|c|c|c|c|c|}
\hline \multirow{2}{*}{$\begin{array}{l}\text { Type } \\
\text { Product name }\end{array}$} & \multicolumn{6}{|c|}{ Log periodic } \\
\hline & \multicolumn{4}{|c|}{ Create design CLP-5130-1 } & \multicolumn{2}{|l|}{ Create design CLP-5130-3 } \\
\hline Frequency range & \multicolumn{4}{|c|}{$59-1300 \mathrm{MHz}$} & \multicolumn{2}{|l|}{$80-250 \mathrm{MHz}$} \\
\hline Gain & \multicolumn{4}{|c|}{ 10-12 dBi (10 dBi at $110 \mathrm{MHz})$} & \multicolumn{2}{|l|}{$12-13 \mathrm{dBi}(12 \mathrm{dBi}$ at $110 \mathrm{MHz})$} \\
\hline Direction & South & West & West & West & Southwest & North \\
\hline Polarization & Horizontal & Vertical & Horizontal & Horizontal & Vertical & Horizontal \\
\hline \multicolumn{7}{|c|}{ (c) Band-pass filter } \\
\hline Product name & Not used & Not used & AOR ABF128 & AOR ABF128 & Not used & Not used \\
\hline Frequency range & - & - & $108-136 \mathrm{MHz}$ & $108-136 \mathrm{MHz}$ & - & - \\
\hline Insertion loss & - & - & $4 \mathrm{~dB}$ & $4 \mathrm{~dB}$ & - & - \\
\hline
\end{tabular}

creating plots for the near real-time visualization and detailed data analyses, the signal intensity values are integrated for $10 \mathrm{~s}$ (i.e., 5 data points) to further improve the signal-to-noise ratio.
Figure 3a shows the locations of the network observation systems composed of 6 receiving $(\mathrm{Rx})$ stations extending from Onna, Okinawa to Sarobetsu, Hokkaido. The locations of these $\mathrm{Rx}$ stations are summarized in
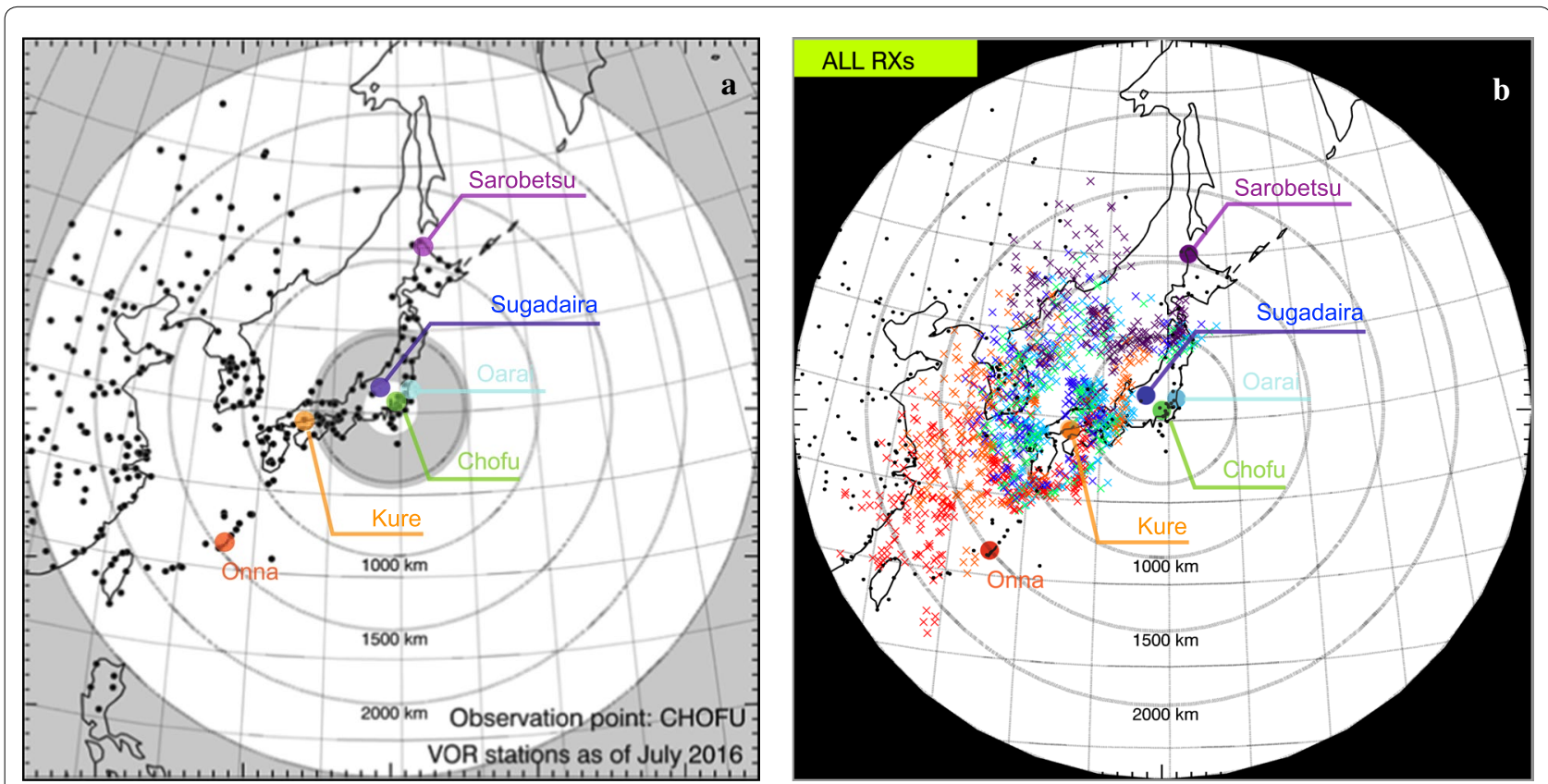

Fig. 3 Distribution of the Tx/Rx stations and corresponding sensing area. a Map of 6 Rx stations (Sarobetsu, Sugadaira, Oarai, Chofu, Kure and Onna), VOR Tx stations (black dots) and the Es propagation zone centered at Chofu. The small white disc near the center represents the normal (ground wave) propagation zone. The small gray doughnut-shaped area corresponds to the skip zone. Radio waves from very high-frequency stations located within the large white zone, the range between 600 and $2500 \mathrm{~km}$ from the receiving station, may propagate to the receiving station due to ionospheric reflection by the Es layer. $\mathbf{b}$ Distribution of mid-point between the $T x$ and Rx stations, which corresponds to the sensing area of the current Es observations 
Table 1. The black dots in Fig. 3a give the distribution of transmitting (Tx) stations of VOR/ILS LOC in eastern Asia. Information on the location of VOR/ILS LOC stations has been obtained from Aeronautical Information Service, or equivalent services, provided by following countries: Japan, Korea, Taiwan, China, and Philippines (e.g., https://aisjapan.mlit.go.jp). In this figure, the center of the concentric circles is Chofu, Tokyo, one of the $\mathrm{Rx}$ stations. The closest most-white area indicates the range of direct propagation (within $200 \mathrm{~km}$ distance) and the outer white area indicates the scope of anomalous propagation (600 to $2500 \mathrm{~km}$ distance). The donut-like gray area between them corresponds to the skip zone. The antenna used by the current observations has a broad beam pattern ( $3 \mathrm{~dB}$ beam width is $\sim 60^{\circ}$ ). At the time of installation, however, we tuned the direction of antenna to maximize the number of Tx stations within its fieldof-view. The direction of antenna is given in Table 1. As shown in Fig. 1, the location of Es can be mapped on the mid-point of $\mathrm{Rx}$ and $\mathrm{Tx}$ stations (i.e., reflection point) using the observed EsAP signals. The colored crosses in Fig. 3b show the spatial distribution of such reflection points. The color respectively represents the $\mathrm{Rx}$ station; for example, the orange crosses give the mid-points between the Rx station in Kure and all the Tx stations (black dots). The distribution of mid-points densely covers a wide area extending from the mainland of Japan to China.

\section{Results}

We have started the full operation of Rx systems at 6 places in Japan since May 1, 2019. Figure 4 shows an example of EsAP event which occurred on July 4, 2019. On this day, Es-related anomalous propagation was detected at all the 6 stations. The data are displayed in a format of spectrogram, in which the horizontal axis is local time (Japan Standard Time: JST $=\mathrm{UT}+9 \mathrm{~h}$ ) and the vertical axis is the frequency of aeronautical navigation signals ranging from 108 to $118 \mathrm{MHz}$. In these spectrograms, the intensity of received signals, derived every $10 \mathrm{~s}$, is color-scaled for each channel (i.e., frequency). Note that continuous high-intensity signals seen throughout the entire day are waves from Tx stations within the range of direct propagation. For example, the receiver at Chofu records a continuous intense signal from the Tx station of VOR at Tokyo/Haneda airport (at 112.2 $\mathrm{MHz}$, about $22 \mathrm{~km}$ from Chofu) which is indicated by the white dot in Fig. 4c.

Clearest signatures of EsAP are seen in the data from Chofu (CF2: Fig. 4c) and Oarai (ORI: Fig. 4d), in which

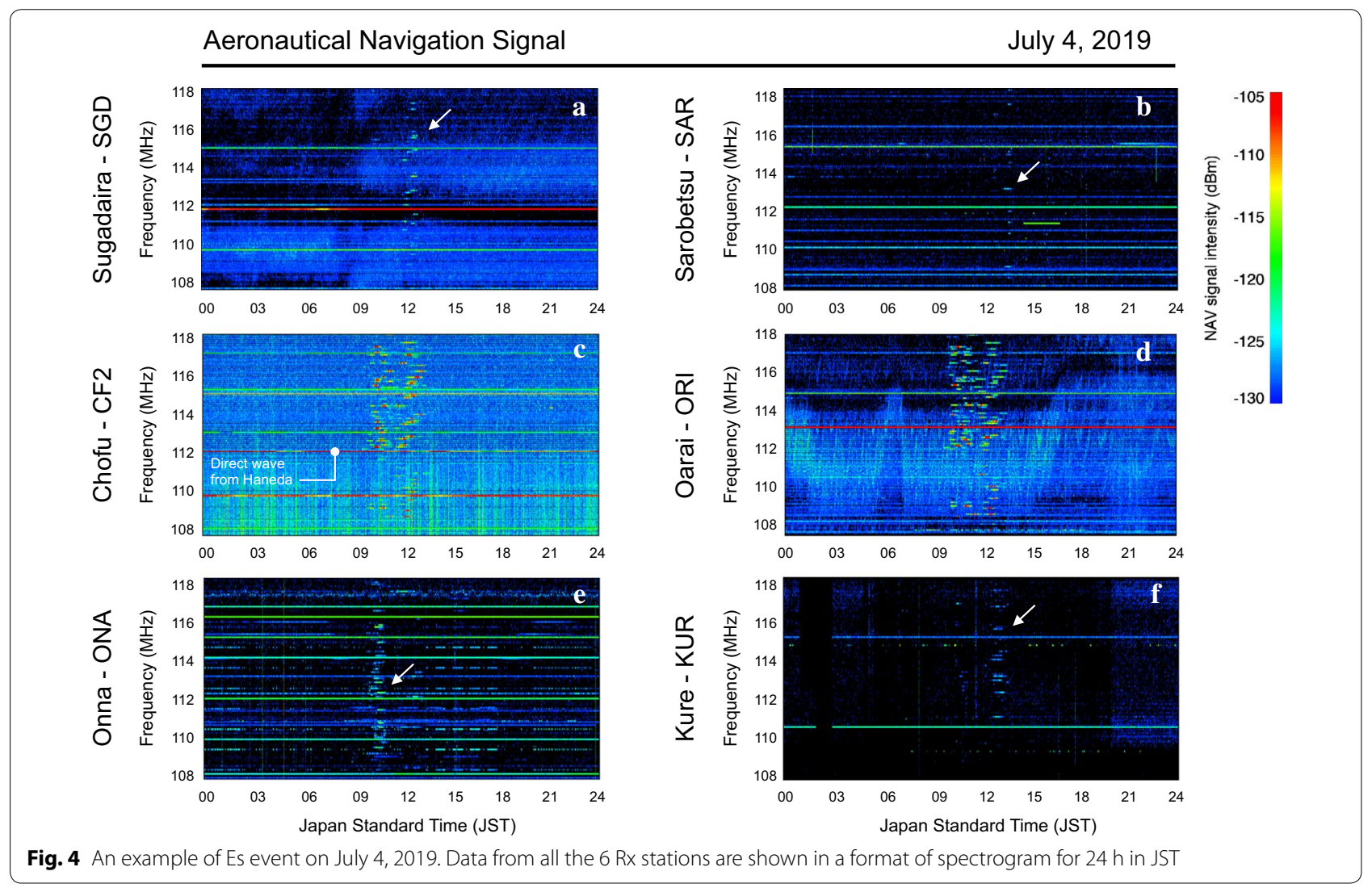


a number of horizontal greenish/yellowish/reddish bars, showing signal intensities higher than $-120 \mathrm{dBm}$, are seen in the spectrograms. These are manifestations of EsAP in the spectrogram. At these stations, the signatures of EsAP continued for $\sim 4 \mathrm{~h}$ from 09 to 13 JST with a brief suspension at around 11 JST. This infers that two individual traces of Es existed in this time interval and passed through the sensing area of each Rx station sequentially. In the spectrograms from other $\mathrm{Rx}$ stations (SGD, SAR, ONA and KUR), although the signature is less clear due to relatively lower signal intensity, similar horizontal bluish/greenish bars are seen as indicated by the white arrows. At these stations, we only observed one of the two Es traces detected at Chofu and Oarai. For instance, the receiver at Onna only detected the first one and the remaining three stations only observed the second one. Such a difference between the stations can be used to infer the localized appearance of Es. According to the simultaneous GPS Rate of Total Electron Content Index (GPS ROTI: Pi et al. 1997) map at 10:30 JST (time of the first Es event), the Es trace was located in the western part of the mainland of Japan. This Es trace was actually within the skip zones of the receivers at Sugadaira and Kure. This should be the reason for the absence of EsAP at Sugadaira and Kure at this timing.

Figure 5 summarizes additional observations of Es by the ionosondes operated by NICT. As shown in Fig. 5a, the ionosondes are operative at 4 stations in Japan (Okinawa, Yamagawa, Kokubunji and Wakkanai). The ionosondes are only able to detect Es that appears

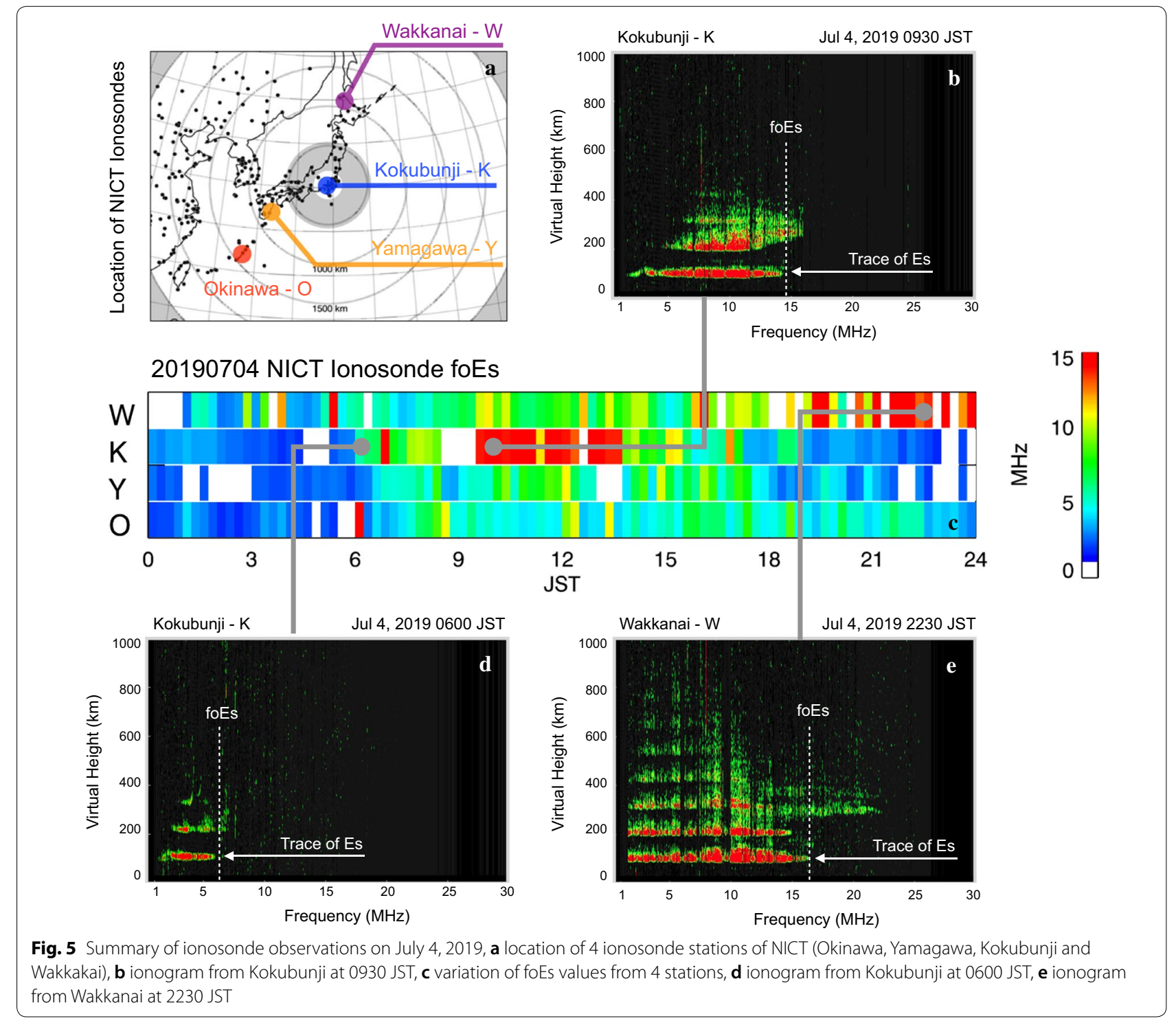


relatively close to the sites. However, they can provide a reliable measure of the intensity (i.e., electron density) of Es with a temporal resolution of $15 \mathrm{~min}$. Figure $5 \mathrm{~b}$ shows the ionosonde data in a format of so-called ionogram obtained from the Kokubunji station in Tokyo at 09:30 JST on July 4, 2019. An outstanding trace of reflection is seen at around $100 \mathrm{~km}$ altitude (i.e., the altitude of Es) from 1 to $\sim 15 \mathrm{MHz}$. This ionogram indicates that Es appeared at this timing and the electron density was sufficiently high to reflect $\sim 15 \mathrm{MHz}$ radio waves of vertical incidence. If we consider more oblique incidence of radio waves, this Es event may cause anomalous propagation of aeronautical VHF waves at 108 to $118 \mathrm{MHz}$ range. Recently, Sakai et al. (2020) demonstrated how the oblique NAV signals propagate for a long distance through Es reflection. According to Fig. 6 of Sakai et al. (2020), the maximum incident angle of the oblique propagation of VHF NAV signals is $\sim 80^{\circ}$. If we consider such oblique long-range propagation of $110 \mathrm{MHz}$ radio with the incident angle of $80^{\circ}$, the electron density should be as high as $4 \times 10^{12} \mathrm{~m}^{-3}$, which corresponds to the critical frequency of $18 \mathrm{MHz}$. This estimation is roughly consistent with the foEs values from the ionosonde.

Figure $5 \mathrm{c}$ indicates the temporal variations of foEs from 4 ionosonde stations, which is a critical frequency of radio waves that are reflected by Es at around $100 \mathrm{~km}$ altitude. Before 09:30 JST, foEs was mostly less than $10 \mathrm{MHz}$ as shown in Fig. 5d. After 09:30 JST a strong Es appeared near the Kokubunji station (K) and continued until 13:30 JST during which the corresponding foEs value was well higher than $15 \mathrm{MHz}$. This Es actually caused the anomalous propagation detected by the VHF observations at Chofu and Oarai (Fig. 4c, d), both of which are located relatively close to the ionosonde at Kokubunji. In the evening, there existed another enhancement of foEs up to $17 \mathrm{MHz}$ in Wakkanai (Fig. 5e). In the VHF radio observations, however, there was no corresponding occurrence of EsAP. This is simply because the sensing area of the VHF receiver at Wakkanai does not cover the ionosphere immediately above the $\mathrm{Rx}$ station. Thus, there is not always one-to-one correspondence between the enhancement of foEs and the occurrence of anomalous propagation at the same observation site, which is often the case for the observations in Okinawa where the VHF receiver is located close to the ionosonde site.

\section{Discussion}

One of the main purposes of the current VHF radio observations is to estimate the spatial distribution of Es in two-dimensional fashion. To obtain the distribution of Es in such a manner, first we need to map the mid-points of Tx and Rx stations for all the EsAP signals in the geographic coordinate system. Figure 6 plots the mid-points of all the EsAP signals at 10:30 and 12:30 JST on July 4, 2019. At 10:30 JST (Fig. 6a), most of the anomalous propagations were detected at the Rx stations in Onna (red), Chofu (light green) and Oarai (blue). Here, we map all the

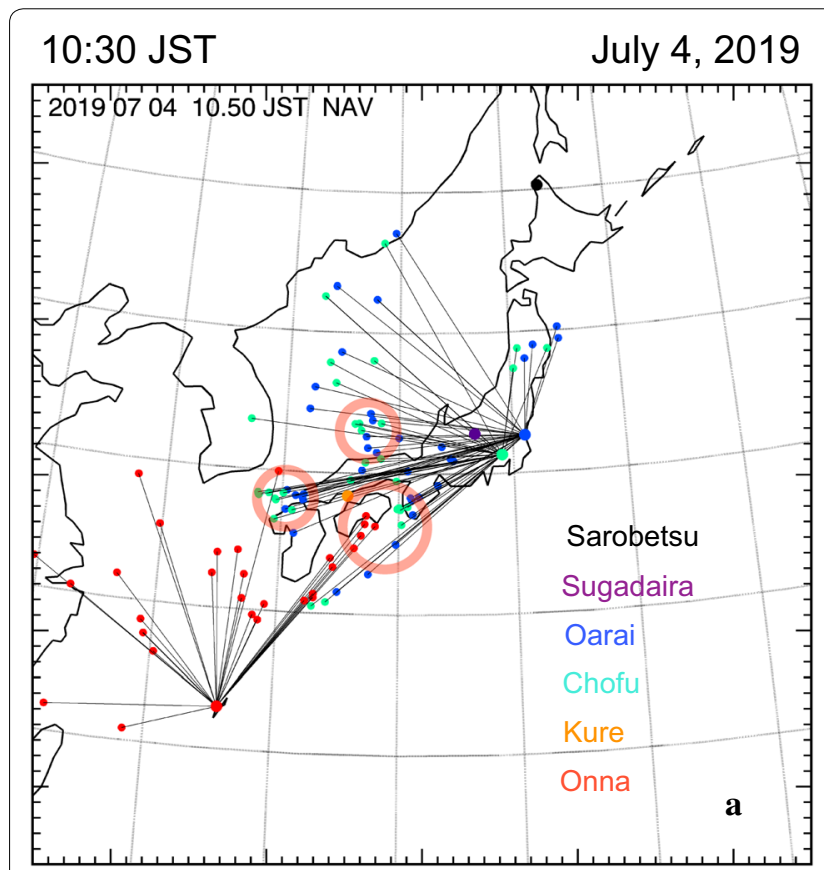

12:30 JST

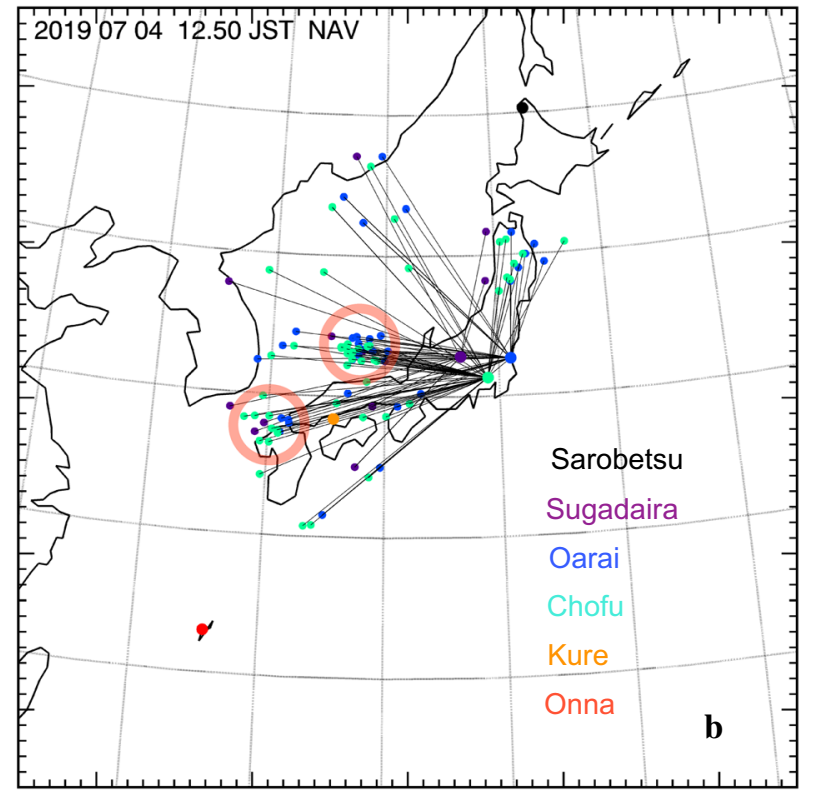

Fig. 6 Distribution of mid-points of Tx and Rx stations for all the detected anomalous propagation at 10:30 JST (a) and 12:30 JST (b) on July 4, 2019 
mid-points of EsAP signals of VOR and ILS LOC. Since we only know the frequency of detected EsAP signals and several VOR/ILS LOC stations use the same frequency, it is difficult to pinpoint the source Tx station only from the current observations. Thus, in this figure, we simply map the mid-points of EsAP between the Rx stations and all the possible Tx stations. This means that the distribution of mid-points in Fig. 6 contains "imaginary points" which are not true reflection points (i.e., ghost points). In actual, the data at 10:30 JST in Fig. 6a indicate that the distribution of the mid-points is scattered in space and relatively isolated points must be the imaginary points. However, there are several clusters of mid-points, for example indicated by the red circles. Those points are considered to represent the actual reflection point of Es.

The data at 12:30 JST in Fig. 6b show that there are again outstanding clusters of mid-points indicated by the red circles, which are considered as a part of the traces of Es. These mapping results imply that it would be possible to obtain the full distribution of Es traces by combining the current dataset with different 2D mapping technique such as GPS-TEC (Maeda and Heki 2014, 2015) and InSAR (Maeda et al. 2016; Furuya et al. 2017). Note that we have only plotted the mid-points of EsAP signals whose intensity is larger than $-120 \mathrm{dBm}$. Thus, although some weak EsAP signals, whose intensity is less than this threshold, were received at Sarobetsu and Kure, the corresponding mid-points of those signals are not plotted in Fig. 6b.

NAV signals contain the station ID as embedded Morse codes. Thus, if we decode those Morse codes, we are able to pinpoint the source station. To simplify the observation system, however, we are not decoding the embedded Morse codes. Instead, as described above, we simply pick up all the possible source stations by comparing the observed frequencies of EsAP and a list of frequency, latitude and longitude of all the VOR and ILS LOC stations. In this case, as shown in Fig. 6, we need an additional step to extract real mid-points by considering the level of mid-point concentration through visual inspection, which is time-consuming and somewhat arbitrary process. Thus, now we are developing an algorithm for picking up the real mid-points automatically using the level of point concentration, which will be reported once we finish validating the feasibility of the approach.

The other purpose of the current VHF radio observations is to construct a system that can monitor the occurrence of Es in near real-time. This function is of particular importance for airlines which use the aeronautical VHF radios for navigating their aircrafts. Figure 7 shows how our near real-time system provides information through WWW. When the users access http://gwave.cei.uec. ac.jp/cgi-bin/vor/vhf.cgi, they can check the occurrence of EsAP in the 6 spectrograms on the bottom. The data from one Rx station are divided into two spectrograms. The upper one shows the data in the aeronautical NAV signal (i.e., from 108 to $118 \mathrm{MHz}$ ). The SDR used in the current observations can capture the signals in a $20 \mathrm{MHz}$ frequency range. This enables us to observe slightly longer wavelengths in the broadcasting channels from 98 to $108 \mathrm{MHz}$, which are shown in the lower spectrogram. Since the lower frequency signals can be reflected by a weaker Es; thus, the signature of EsAP tends to be more prominent in the broadcasting channels, for example the data from Kure and Onna, on the right-hand side of the bottom panels in Fig. 7. As mentioned in the previous part, the data and corresponding plots are refreshed every $1 \mathrm{~h}$. Hence, if the airlines find any problems in receiving the aeronautical VHF signals during their flights, they can check if the detected problems are due to instrumental problem or due to interference caused by Es anomalous propagation after the arrival.

The website also displays the variation of foEs from the 4 ionosonde stations of NICT in a near real-time basis. The top three panels, which are identical, show the foEs values from 4 ionosonde stations (W, K, Y, and O). The warmer colored periods indicate the occurrence of Es. Figure 7 shows data from August 3, 2019. On this day, significant enhancement of foEs is seen in the early evening from 17 to $20 \mathrm{JST}$. In this time period, the VHF radio observations indicate clear signatures of EsAP at all the stations except for Sarobetsu, northernmost station in Hokkaido. By combining the VHF radio observations together with the foEs values from the ionosondes, we could infer the time/location of Es causing the anomalous propagation. This website also offers a capability of showing data from previous periods. Users can browse the interval of their interest by specifying the date on top of the page. This will further enable the users to check the appearance of Es not only for evaluating the aeronautical navigation environment but also for analyzing the ionospheric data for scientific purposes.

\section{Summary}

We introduced a network observation of VHF radio signals for monitoring the anomalous propagation of aeronautical VHF signals due to sporadic E. The occurrence of Es-related anomalous propagation is continuously monitored at $6 \mathrm{Rx}$ stations in Japan. The receiving system covers VHF signals whose frequency ranges from 98 to $118 \mathrm{MHz}$, upper part of which corresponds to the frequency range of the aeronautical navigation system. Using this network observation system, we detected an intense Es event during the daytime on July 4, 2019. On this day, an ionosonde of NICT in Kokubunji, Tokyo identified an occurrence of Es whose foEs was higher than 


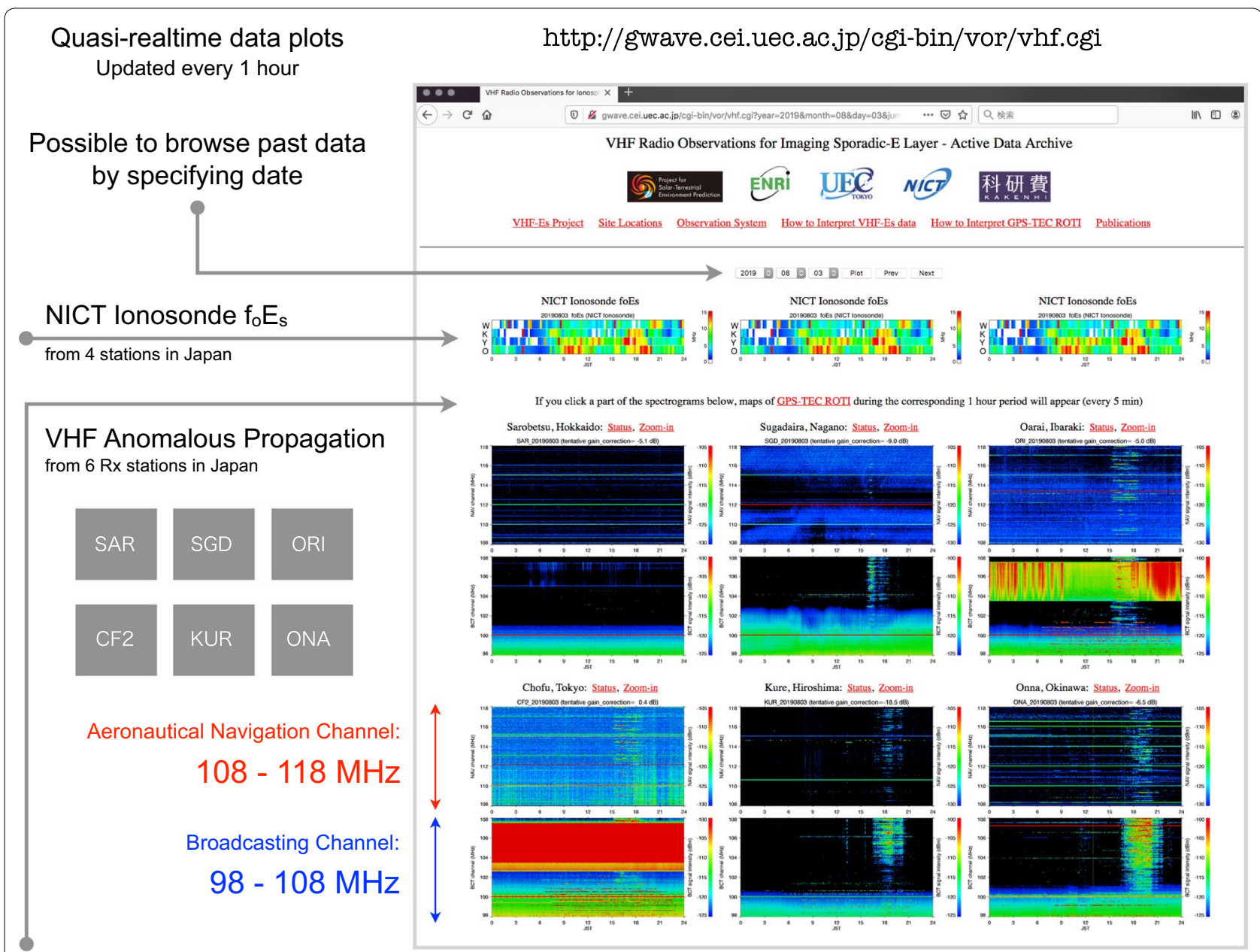

Fig. 7 Near real-time data browsing system for the Es-related anomalous propagation

$15 \mathrm{MHz}$. At the same time, all the $6 \mathrm{Rx}$ stations recorded signatures of anomalous propagation for about $4 \mathrm{~h}$. The correspondence between the enhancement of foEs and the occurrence of anomalous propagation confirms that the current VHF radio observation can be used to detect the appearance of Es. This means that the data can also be used to infer the spatial distribution of Es although it is needed to develop an algorithm to distinguish the real signatures of Es from the imaginary points, which is now under development. As pointed out in the ICAO document, anomalous propagation due to Es is one of the possible space weather threats in the ionosphere. To routinely monitor such an impact, the data from the VHF radio observation together with those from ionosonde of NICT are displayed in near real-time at http://gwave.cei. uec.ac.jp/cgi-bin/vor/vhf.cgi. In near future, we plan to extend the network by deploying additional receiving stations in Taiwan, Korea and the mainland of China, which will enhance the coverage of the measurement.

\section{Abbreviations}

Es: Sporadic E; EsAP: Sporadic E anomalous propagation; GAIA: Ground-totopside model of Atmosphere and lonosphere for Aeronomy; TEC: Total electron content; GBAS VDB: Ground-based augmentation system VHF data broadcast; GNSS: Global Navigation Satellite System; GPS: Global positioning system; ICAO: International Civil Aviation Organization; ILS LOC: Instrumental Landing System LOCalizer; JST: Japan Standard Time; NICT: National Institute of Information and Communications; SDR: Software-defined radio; UT: Universal time; VHF: Very high-frequency; VOR: VHF omni range.

\section{Acknowledgements}

$\mathrm{KH}$ thanks the staff of A. Nadai and M. Oshiro at the Okinawa Electromagnetic Technology Center of National Institute of Information and Communications Technology for supporting the VHF radio observation at Onna, Okinawa. KH also thanks A. Yamamoto at Japan Coast Guard Academy for supporting the VHF radio observation at Kure, Hiroshima. KH also thanks T. Yamahata for his efforts of developing the on-site observation software.

\section{Authors' contributions}

$\mathrm{KH}$ designed and conducted the current research and prepared the manuscript. JS and SS analyzed the VHF radio observation data. IT developed the observation system. TT, MN and Ml operated the ionosonde observations of NICT and helped the interpretation of the results. All authors read and approved the final manuscript. 


\section{Funding}

KH is supported by JSPS-Kakenhi (18H04437). A part of this work was supported by JSPS KAKENHI Grant Number JP15H05813, "The Project for SolarTerrestrial Environment Prediction (PSTEP)".

\section{Availability of data and materials}

Data of VHF radio observations introduced in this paper are available upon request (contact: Keisuke Hosokawa). Ionosonde's foEs data were provided by WDC for lonosphere and Space Weather, Tokyo, National Institute of Information and Communications Technology (http://wdc.nict.go.jp/IONO/index _E.html).

\section{Ethics approval and consent to participate}

Not applicable.

\section{Consent for publication}

Not applicable.

\section{Competing interests}

The authors declare that they have no competing interests.

\section{Author details}

${ }^{1}$ University of Electro-Communications, Chofugaoka 1-5-1, Chofu, Tokyo 182-8585, Japan. ${ }^{2}$ Center for Space Science and Radio Engineering, University of Electro-Communications, Chofugaoka 1-5-1, Chofu, Tokyo 182-8585, Japan. ${ }^{3}$ Electronic Navigation Research Institute, National Institute of Maritime, Port and Aviation Technology, Jindaiji-Higashicho 7-42-23, Chofu, Tokyo 182-0012, Japan. ${ }^{4}$ National Institute of Information and Communications Technology, Nukui-Kitamachi 4-2-1, Koganei, Tokyo 184-8795, Japan.

Received: 23 April 2020 Accepted: 20 June 2020

Published online: 01 July 2020

\section{References}

Davies K (1969) lonospheric radio waves. Blaisdell, Waltham

Davis RM, Smith EK, Ellyett CD (1959) Sporadic E at VHF in the USA. Proc IRE 9:762-769. https://doi.org/10.1109/JRPROC.1959.287271

Furuya M, Suzuki T, Maeda J, Heki K (2017) Midlatitude sporadic-E episodes viewed by L-band split-spectrum InSAR. Earth Planets Space 69:175. https ://doi.org/10.1186/s40623-017-0764-6

Haldoupis C (2011) A tutorial review on sporadic E layers. In: Abdu MA, Pancheva D, Bhattacharyya A (eds) Aeronomy of the Earth's atmosphere and ionosphere. Springer-Verlag, Berlin, pp 381-394

ICAO APANPIRG CNS-SG ISTF/6-WP/4, Potential operational improvements through space weather services to help mitigate the effects of space weather on the regional CNS systems and operations, ISTF/6, Bangkok, Thailand, January 2016
ICAO APANPIRG CNS-SG/20-WP/21, Report of lonospheric Studies Task Force Activities, APANPIRG CNS-SG/20, Bangkok, Thailand, July 2016

ICAO, International Civil Aviation Organization (2018) International standards and recommended practices, Annex 10 to the Convention on the International Civil Aviation, 7th edition, November 2014

Maeda J, Heki K (2014) Two-dimensional observations of midlatitude sporadic E irregularities with a dense GPS array in Japan. Radio Sci 49:28-35. https ://doi.org/10.1002/2013RS005295

Maeda J, Heki K (2015) Morphology and dynamics of daytime mid-latitude sporadic-E patches revealed by GPS total electron content observations in Japan. Earth Planets Space 67:89. https://doi.org/10.11186/s4062 3-015-0257-4

Maeda J, Suzuki T, Furuya M, Heki K (2016) Imaging the midlatitude sporadic E plasma patches with a coordinated observation of spaceborne InSAR and GPS total electron content. Geophys Res Lett 43:1419-1425. https:// doi.org/10.1002/2015GL067585

Mathews JD (1998) Sporadic E: current views and recent progress. J Atmos Terrest Phys 60:413-435. https://doi.org/10.1016/S1364-6826(97)00043-6

Pi X, Mannucci AJ, Lindqwister UJ, Ho CM (1997) Monitoring of global ionospheric irregularities using the worldwide GPS network. Geophys Res Lett 24(18):2283-2286. https://doi.org/10.1029/97GL02273

Rice DD, Sojka JJ, Eccles JV, Raitt JW, Brady JJ, Hunsucker RD (2011) First results of mapping sporadic E with a passive observing network. Space Weather 9:S12001. https://doi.org/10.1029/2011SW000678

Sakai J, Hosokawa K, Tomizawa I, Saito S (2019) A statistical study of anomalous VHF propagation due to the sporadic-E layer in the air-navigation band. Radio Sci 54:426-439. https://doi.org/10.1029/2018RS006781

Sakai J, Saito S, Hosokawa K, Tomizawa I (2020) Anomalous propagation of radio waves from distant ILS localizers due to ionospheric sporadic-E. Space Weather 18:e2020SW002517. https://doi.org/10.1029/2020SW0025 17

Shinagawa H, Miyoshi Y, Jin H, Fujiwara H (2017) Global distribution of neutral wind shear associated with sporadic $E$ layers derived from GAIA. J Geophys Res Space Phys 122:4450-4465. https://doi.org/10.1002/2016J A023778

Whitehead JD (1989) Recent work on mid-latitude and equatorial sporadic-E. J Atmos Solar Terrest Phys 51:401-424. https://doi.org/10.1016/00219169(89)90122-0

Wu DL, Ao CO, Hajj GA, de la Torre Juarez M, Mannucci AJ (2005) Sporadic E morphology from GPS-CHAMP radio occultation. J Geophys Res 110:A01306. https://doi.org/10.1029/2004JA010701

\section{Publisher's Note}

Springer Nature remains neutral with regard to jurisdictional claims in published maps and institutional affiliations.

\section{Submit your manuscript to a SpringerOpen ${ }^{\circ}$ journal and benefit from:}

- Convenient online submission

- Rigorous peer review

- Open access: articles freely available online

- High visibility within the field

- Retaining the copyright to your article

Submit your next manuscript at $\boldsymbol{\nabla}$ springeropen.com 